\title{
Knowledge, Attitude, and Psychological Impacts of COVID-19 in Saudi Arabia
}

\section{OPEN ACCESS}

Edited by:

Harshad Thakur,

Tata Institute of Social Sciences, India

Reviewed by:

Eman Zmaily Dahmash,

Isra University, Jordan

Idir Mechai,

Jazan University, Saudi Arabia

*Correspondence:

Naif Alanaz

n.alanazi@seu.edu.sa

Specialty section:

This article was submitted to

Public Health Education and

Promotion,

a section of the journal

Frontiers in Public Health

Received: 25 October 2021

Accepted: 26 January 2022

Published: 23 February 2022

Citation:

Alanazi N and Bahjiri K (2022)

Knowledge, Attitude, and

Psychological Impacts of COVID-19 in

Saudi Arabia.

Front. Public Health 10:801777.

doi: 10.3389/fpubh.2022.801777

\author{
Naif Alanazi ${ }^{1 *}$ and Khaled Bahjri ${ }^{2}$ \\ ${ }^{1}$ Department of Public Health, College of Health Science, Saudi Electronic University, Riyadh, Saudi Arabia, ${ }^{2}$ Department of \\ Pharmaceutical and Administrative Sciences, Loma Linda, CA, United States
}

Background: The world has been facing an unprecedented pandemic of COVID-19 with over 336 million people infected and millions of deaths. This required an enormous communication effort response from governments, international, and individuals to keep the public informed about the outbreak. When a pandemic affects communities, individuals' knowledge and attitude are important factors to contain the outbreak. Thus, the purpose of this study is to measure individuals' knowledge and attitude toward COVID-19 and ascertain whether a need exists for mental health services for those who were affected by the pandemic.

Methods: A cross-sectional design was used to measure the knowledge, attitude, and psychological impacts about the COVID-19 pandemic among the Saudi population. Research participants were recruited using a snowball sampling technique through the social media platform WhatsApp. A total of 482 eligible individuals participated from various locations in Saudi Arabia represented almost all Saudi regions. The questionnaire consisted of seven questions evaluating knowledge, seven gauging attitudes, and 16 questions assessing anxiety and perceived need for mental healthcare services.

Results: A modest level of knowledge (59\%) was found among the Saudi population sampled about the COVID-19 pandemic, and satisfactory knowledge (>80\%) about its preventive measures. Anxiety and stress existed among the participants (79\% obsessed with COVID-19), with an 88\% approval rate for obtaining mental health services for individuals highly affected by the pandemic.

Conclusion: There is a need to increase awareness and provide continuous updates regarding the pandemic situation. Promoting access to mental health services is critical, as well as finding creative and suitable strategies to deliver mental health services to those who need them.

Keywords: COVID-19 knowledge, attitude, mental health perceptions, coronvirus-2019 stress and anxiety, knowledge and attitude 


\section{INTRODUCTION}

The family of coronaviruses has been responsible for three outbreaks in the last 20 years. The earliest pandemic, severe acute respiratory syndrome coronavirus (SARS-CoV) occurred in China 2002-2003 (1), followed by Middle East respiratory syndrome coronavirus (MERS-CoV), which surged in Saudi Arabia in 2012 (2). The worst pandemic in our lifetime emerged in 2019 in Wuhan, China, widely known as COVID-19. This novel coronavirus was named by the International Committee on Taxonomy Virology (ICTV) as severe acute respiratory syndrome coronavirus-2 (SARS-CoV-2) (3). COVID-19 differs from other coronaviruses in terms of its high transmissibility from person to person, and pathological shedding, which may persist longer than SARS-CoV and MERS-CoV (4). As a result, on March 11, 2020, the World Health Organization (WHO) identified COVID-19 as a global pandemic.

As of January 2022, there were $\sim 336$ million confirmed cases of COVID-19, with over 5.5 million confirmed deaths worldwide (5). These numbers are expected to increase as new variants of the virus surge around the world. In fact, COVID-19 has had a wider effect than any virus in its genus. In addition, COVID19 has impacted all aspects of life worldwide. Its surge and rapid spread have caused chaos, anxiety, and a multitude of concerns at the local, national, and international levels. Social and economic activities have been curtailed by lockdowns and quarantine measures, initiating a series of adverse economic, public health, and environmental consequences (6). The virus has changed the world significantly, taking a significant toll on individuals, families, and communities (7). Fundamental changes have been seen in our social, communication, thoughts, working, and even physical appearance.

The world continues to deal with the effects of the pandemic as new variants emerge and spread. High rates of infection and a rising death toll creates pressure on global governments to collaborate on ways to contain the outbreak. This in turn places a huge responsibility on individuals, communities, and governments to limit further health, social, and economic devastation caused by the pandemic. While governments are leading large-scale efforts toward virus containment, in fact, it is individuals who are the cornerstone of the containment efforts of this pandemic (8). It is likely that individuals' knowledge and attitudes toward COVID-19 explains the speed of transmission in different societies. Individuals' health literacy and attitude toward the virus symptoms and modes of transmission and, use of personal protection equipment can play a role in the rate of infection. Individuals can protect themselves, their families, and communities by social distancing, wearing face masks, washing hands frequently, and most importantly getting vaccinated. Mathematical models conducted exclusively in the Saudi population to predict biological and epidemiological predispositions toward COVID-19 found that social distancing, personal hygiene, and travel restrictions were vital measures to prevent the outbreak's spread (9). Evaluating whether individuals aware, embrace, or ignore these measures can provide authorities with insight into how open a given community or region is to adopting measures to deal with the pandemic. Evidence-based data about knowledge and attitudes of COVID-19 outbreak can help health officials to develop effective interventions and policies that are appropriate to a particular population (10). Several studies have shown that individuals lack knowledge about microbial infections in the general population. A lack of community knowledge about disease transmission can impede efforts to control the pandemic $(11,12)$.

Knowledge and attitudes toward COVID-19 prevention behaviors can be explained by many factors, including gender, educational level, geographical area, socioeconomic status, access to healthcare services, and level of pandemic burden. Generally, when a pandemic hits, knowledge and attitude levels are usually not aligned with the protective actions needed to slow or stop transmission. In order to understand human behaviors, it is crucial to know the knowledge and attitude when people take actions for themselves (13). Therefore, the purpose of this study is to measure individuals' knowledge and attitude toward COVID19 to know the effectiveness of the protective actions taken by health officials in Saudi Arabia. Furthermore, it is also likely that the pandemic will cause adverse psychological impacts across society in general. The study of individuals' anxiety and stress may help health officials effectively manage the pandemic and understand the mental health status of the population. This may turn health authorities' attention to providing mental health services for those adversely affected by the pandemic (13). As a result, this study sought to measure the level of anxiety associated with the COVID-19 outbreak and provide insight into the perceived mental health needs among the target population of Saudi citizens.

\section{METHODS}

A cross-sectional design study was used to measure the knowledge and attitudes that exist in Saudi population regarding COVID-19. A total of 482 individuals responded to the online survey. Research participants were recruited using the snowball sampling technique through WhatsApp, one of the most popular social media platforms in Saudi Arabia. The self-administered, online survey was developed using Qualtrics XM software, Version 2020. A consent form was attached, which participants must complete before beginning the survey. A hyperlink to the survey was distributed through WhatsApp to all groups and contacts of the principal investigator, who were encouraged to share it with their own contacts. By clicking on the link, participants would be directed first to the consent form, which they must complete in order to access the research survey.

The survey was provided in both English and Arabic, translated from English to Arabic using Brislin's model $(14,15)$. Eligible participants were 16 years old or older, and able to read either Arabic or English. The data collection process was initiated on March 2021 until the end of May of 2021; data were gathered from various provinces in Saudi Arabia. After starting the survey, participants could stop at any time and complete it at their convenience.

The instrument used in this study was a modified version of one used in a similar study conducted in India (16). The 


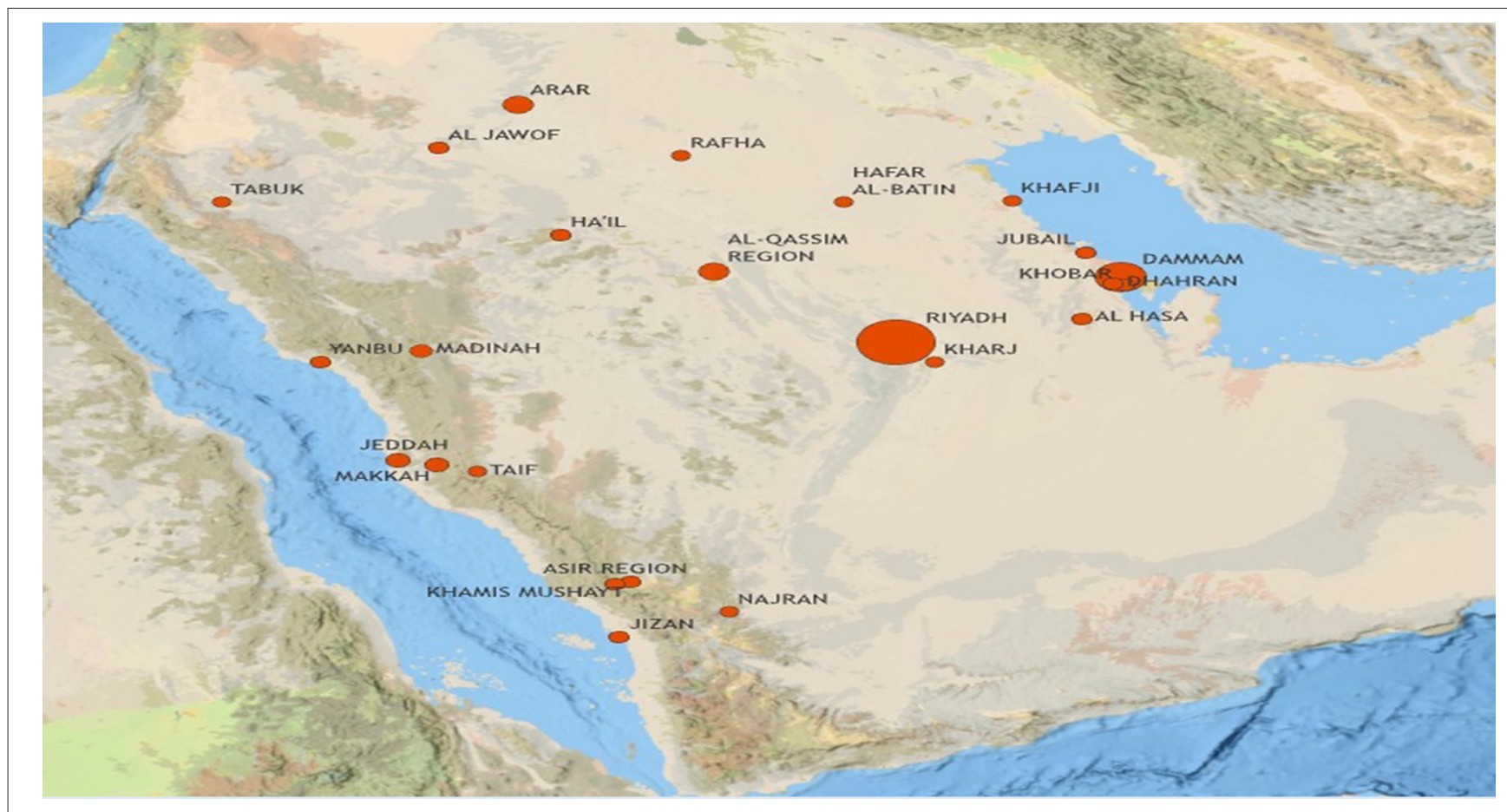

FIGURE 1 | Distribution of study sample across Saudi Arabia.

survey contained five sections. The first section focused on sociodemographic variables including age, gender, marital status, occupation, education level, and area of residence. The second section dealt with COVID-19 awareness (knowledge) with seven multiple choice questions. The third part contained seven 5-point Likert style questions (ranging from strongly agree, agree, do not know, disagree, and strongly disagree) about participants' attitudes about COVID-19. Anxiety regarding COVID-19 was assessed by 13 questions using a 5-point Likert scale (ranging from never, occasionally, sometimes, often, and always). The perception of healthcare need was measured by four 3-point Likert scale questions (yes, maybe, and no).

\section{RESULTS}

\section{Participants' Characteristics}

A total of 482 eligible individuals participated from various locations in Saudi Arabia represented almost all Saudi regions. The high participation rate came from populous cities such as Riyadh, Dammam, Al-Qassim, Jeddah, and Makkah as it is shown in Figure 1.

From the sample collected, 62 participants were found to be under age 16 and therefore excluded from the study. Most of the study participants were young, with the median age $\sim 23$ years old. The number of male participants (53\%) were slightly higher than female participants (47\%). A majority of participants (66\%) were married, and more than $60 \%$ held a bachelor's degree or higher. Only $12 \%$ of participants were in the healthcare field. More demographic details can be found in Table $\mathbf{1 .}$
TABLE 1 | Subject characteristics $(N=482)$.

\begin{tabular}{|c|c|c|c|}
\hline \multicolumn{2}{|l|}{ Age; median (min. to max.) } & \multicolumn{2}{|c|}{$23(16-58)$} \\
\hline Gender & Male & 252 & $53 \%$ \\
\hline & Female & 227 & $47 \%$ \\
\hline \multirow[t]{4}{*}{ Marital status } & Single & 140 & $30 \%$ \\
\hline & Married & 314 & $66 \%$ \\
\hline & Divorced & 16 & $3 \%$ \\
\hline & Widowed & 3 & $1 \%$ \\
\hline \multirow[t]{6}{*}{ Occupation } & Professional & 129 & $27 \%$ \\
\hline & Business & 13 & $3 \%$ \\
\hline & Student & 74 & $15 \%$ \\
\hline & Healthcare & 59 & $12 \%$ \\
\hline & Unemployed & 78 & $16 \%$ \\
\hline & Others & 127 & $26 \%$ \\
\hline \multirow[t]{5}{*}{ Education } & ${ }^{*} \mathrm{HS}$ or less & 99 & $21 \%$ \\
\hline & Diploma & 81 & $17 \%$ \\
\hline & Bachelors & 224 & $47 \%$ \\
\hline & Masters & 47 & $10 \%$ \\
\hline & Doctorate & 28 & $6 \%$ \\
\hline
\end{tabular}

All values are count and percentage except otherwise indicated.

*HS means high school.

\section{Awareness of COVID-19 Outbreak}

Awareness of COVID-19 was found to be moderately high among the study population, as shown in Tables 2-4. Respondents reported essential knowledge of the virus, with most (59\%) believing that COVID-19 was spread through 
TABLE 2 | How does COVID-19 (Coronavirus Disease-2019) spread?

\begin{tabular}{lcc}
\hline & N & $\%$ \\
\hline Touching & 181 & $38 \%$ \\
Sneezing & 191 & $40 \%$ \\
Kissing & 169 & $35 \%$ \\
Food & 31 & $6 \%$ \\
All the above & 285 & $59 \%$ \\
\hline
\end{tabular}

TABLE 3 | COVID-19 infection knowledge.

\begin{tabular}{lcc}
\hline & N & $\%$ \\
\hline How does COVID-19 spread? & 345 & \\
Highly contagious & 72 & $72 \%$ \\
Highly fatal & 350 & $15 \%$ \\
No treatment & 75 & $73 \%$ \\
Transmission cannot be prevented & 48 & $16 \%$ \\
Self-quarantine is ineffective & $1.8 \pm 1.1$ & $10 \%$ \\
COVID-19 spread score (mean \pm & & \\
standard deviation) & & \\
Which of the following can protect you from COVID-19? & $84 \%$ \\
Handwashing & 404 & $83 \%$ \\
Avoiding indoor crowds & 399 & $84 \%$ \\
Face covering and social distancing & 404 & $15 \%$ \\
Touching nose and eyes & 74 & $13 \%$ \\
Reusing masks and gloves & 64 & $13 \%$ \\
Shaking hands & 62 & \\
COVID-19 protection score (mean \pm & & \\
standard deviation) & $2.9 \pm 1.2$ & \\
\end{tabular}

multiple modes such as sneezing, touching, kissing, and ingesting food (see Table 2).

However, a small margin of the participants (6\%) thought the virus was spread solely by food. A significant number of participants recognized that handwashing, avoiding indoor crowds, using face coverings, and social distancing could stop dissemination of the virus. The vast majority of the study participants (90\%) believed that isolating a person with symptoms could stop the spread of the infection. In addition, most of the participants $(>70 \%)$ considered the virus highly contagious and untreatable (see Table 3 ).

Furthermore, participants were able to identify major COVID-19 symptoms such as fever/chill, shortness of breath, cough, loss of taste/smell, and headache. Nevertheless, fewer than half of participants were less aware of symptoms such as fatigue, congestions, nausea/vomiting, and diarrhea as shown in Table 4 and Figure 2.

\section{Attitude Toward COVID-19}

A significant number of participants (89\%) felt that they could be infected by COVID-19; in addition, a super-majority (95\%) agreed with government guidelines and regulations regarding the pandemic. Respondents thought frequent hand-washing and social distancing could slow the spread of the virus, and more
TABLE 4 | What are the symptoms of COVID-19?

\begin{tabular}{lcc}
\hline & N & $\%$ \\
\hline Fever/chills & 381 & $79 \%$ \\
Cough & 291 & $60 \%$ \\
Shortness of breath & 421 & $87 \%$ \\
Fatigue & 189 & $39 \%$ \\
Muscle ache & 294 & $61 \%$ \\
Headache & 336 & $70 \%$ \\
Loss of taste or smell & 373 & $77 \%$ \\
Sore throat & 252 & $52 \%$ \\
Congestions & 153 & $32 \%$ \\
Nausea/vomiting & 143 & $30 \%$ \\
Diarrhea & 231 & $48 \%$ \\
\hline
\end{tabular}

than $96 \%$ said they were likely to quarantine/isolate themselves if they had fever and cough. Nevertheless, more than half of participants (53\%) thought traveling within the country was safe during the pandemic. In addition, $51 \%$ believed that patients who recovered after being infected with the virus should not attend indoor activities or social gatherings. More details of participant attitudes toward COVID-19 can be found in Table 5 .

\section{Anxiety of COVID-19 Pandemic}

As the data of the Table 6 showed, $\sim 79 \%$ of respondents (those who answered maybe, most likely, or definitely) were obsessed with COVID-19 over the previous week. Nearly 57\% of respondents felt paranoid about contracting the coronavirus. About $82 \%$ of participants said they were likely to avoid partying, meeting, and gathering, and $77 \%$ reported they were likely to avoid social contact. COVID-19 was the topic that most participants (76\%) talked about with their friends over the last week. Furthermore, about $28 \%$ of the participants reported having difficulty sleeping due to worries about the pandemic. However, most participants (68\%) did not often feel the need to buy and stock essentials at home. More than half of participants (54\%) felt scared if anyone in their social circle was sick with something that might be COVID-19.

\section{Perceived Mental Healthcare Needs}

The pandemic has been a source of psychological distress worldwide. Data presented in Table 7 and Figure 3 showed that more than $64 \%$ of participants were open to talking to a professional, family, or close friends about concerns associated with COVID-19. Most participants (80\%) felt it was necessary for individuals experiencing fear and anxiety related to the pandemic to seek help from mental health professionals. Furthermore, a significant number of participants (89\%) thought it would be beneficial for mental health professionals to help people deal with the current COVID-19 pandemic. Participants highly approved (88\%) obtaining mental health services for people who are highly affected by the pandemic. 


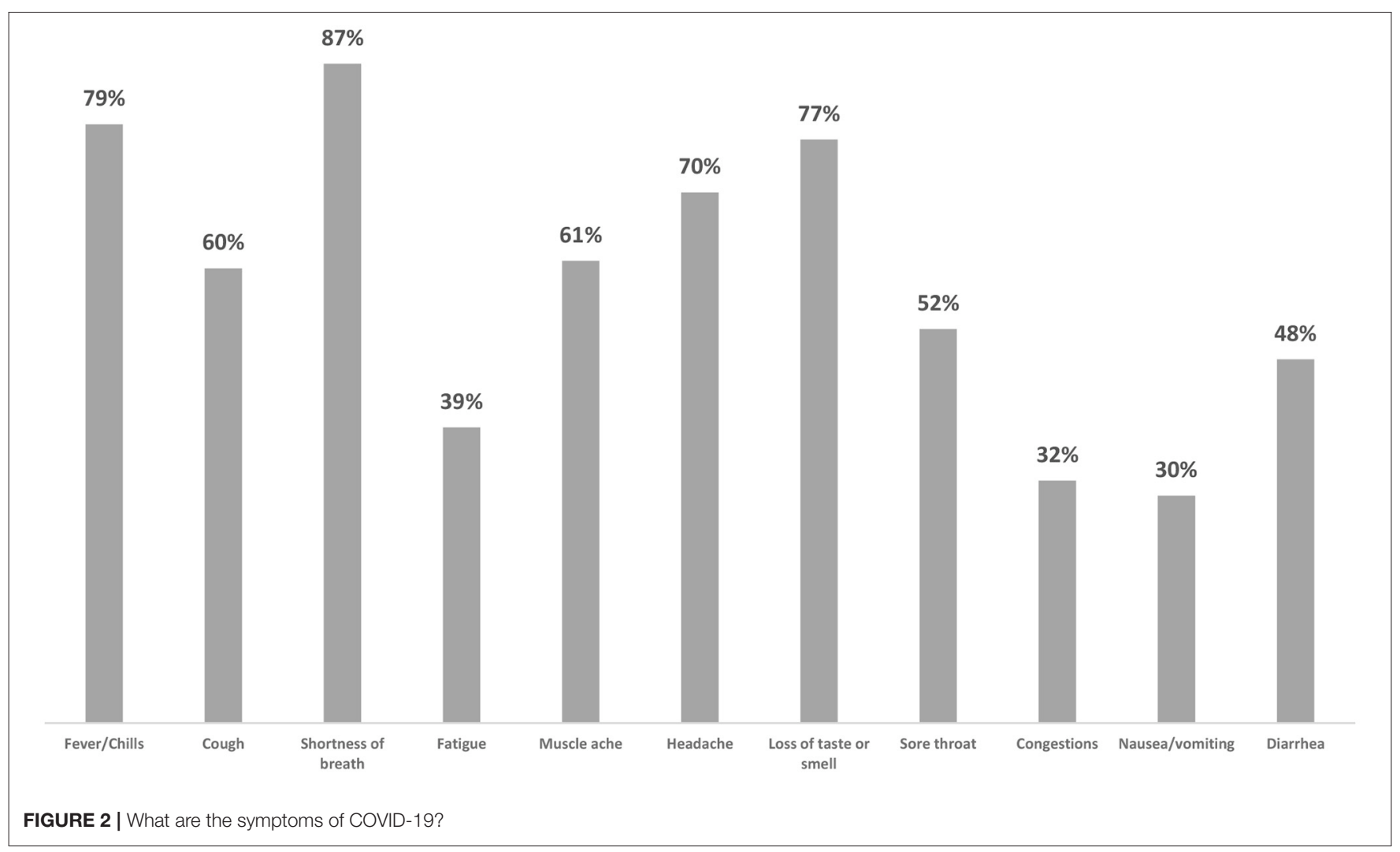

TABLE 5 | Attitude toward COVID-19 infection.

\begin{tabular}{|c|c|c|c|c|c|}
\hline & Never & Unlikely & Maybe & Most likely & Definitely \\
\hline Do you feel you can be affected by the coronavirus? & 15 (3\%) & 37 (8\%) & $197(41 \%)$ & 186 (39\%) & $42(9 \%)$ \\
\hline Would you agree to the government guidelines regarding the coronavirus pandemic? & $17(4 \%)$ & $7(1 \%)$ & $22(5 \%)$ & $227(47 \%)$ & $206(43 \%)$ \\
\hline Do you think washing hands frequently can lower the risk of coronavirus infection? & $13(3 \%)$ & $10(2 \%)$ & $42(9 \%)$ & $219(46 \%)$ & $196(41 \%)$ \\
\hline How likely are you to quarantine/ isolate yourself if you have fever and cough? & $10(2 \%)$ & $4(1 \%)$ & $48(10 \%)$ & $224(47 \%)$ & $193(40 \%)$ \\
\hline Do you think social distancing is essential to stop spread of the coronavirus? & $11(2 \%)$ & $10(2 \%)$ & $17(4 \%)$ & $188(39 \%)$ & $254(53 \%)$ \\
\hline Do you think traveling across/within the country is safe during these times? & $81(17 \%)$ & $147(31 \%)$ & $86(18 \%)$ & $123(26 \%)$ & $43(9 \%)$ \\
\hline Patients who are cured from corona virus should not attend indoor activity or social gathering? & $85(18 \%)$ & $145(30 \%)$ & $111(23 \%)$ & $97(20 \%)$ & $40(8 \%)$ \\
\hline
\end{tabular}

\section{DISCUSSION}

COVID-19 continues to surge around the world, with more than 271 million confirmed cases and over 5 million deaths across nearly 200 countries (5). As the COVID- 19 virus continues to evolve and develop new strains, more COVID-19 cases are expected. Scientists are working tirelessly to learn more about emerging variants, their spread, and whether vaccines will be protective against them. The pandemic is ongoing, therefore, the public must be informed and updated with any new information and developments related to the virus and its variants. As was seen in previous epidemics and pandemics, the populace faces many challenges and hardships. Lack of awareness and accurate information can lead to attitudes and behaviors which work against the goal of slowing the spread of the virus and ending the pandemic. Therefore, this study sought to examine individuals' knowledge and attitudes toward COVID-19. In addition, the study measured levels of anxiety caused be COVID-19 and examined the need for mental health services in Saudi Arabia.

The level of knowledge seemed to be moderately high among study participants, which is similar to other studies conducted among educated people in India $(16)$, Ethiopia $(16,17)$ and other countries (18-20). More specifically, the knowledge level found in this study is congruent with other studies conducted in the Saudi population (21-23). The study provides additional evidence to earlier findings. It seems that government media coverage in Saudi Arabia kept the public highly informed about the pandemic. It is worth mentioning that the data collection was not during the early stages of the pandemic, and hence higher level of awareness is expected. Furthermore, non-government outlets and social media platforms increased their coverage as the number of COVID-19 cases increased. The media, in 
TABLE 6 | Anxiety associated with COVID-19 infection.

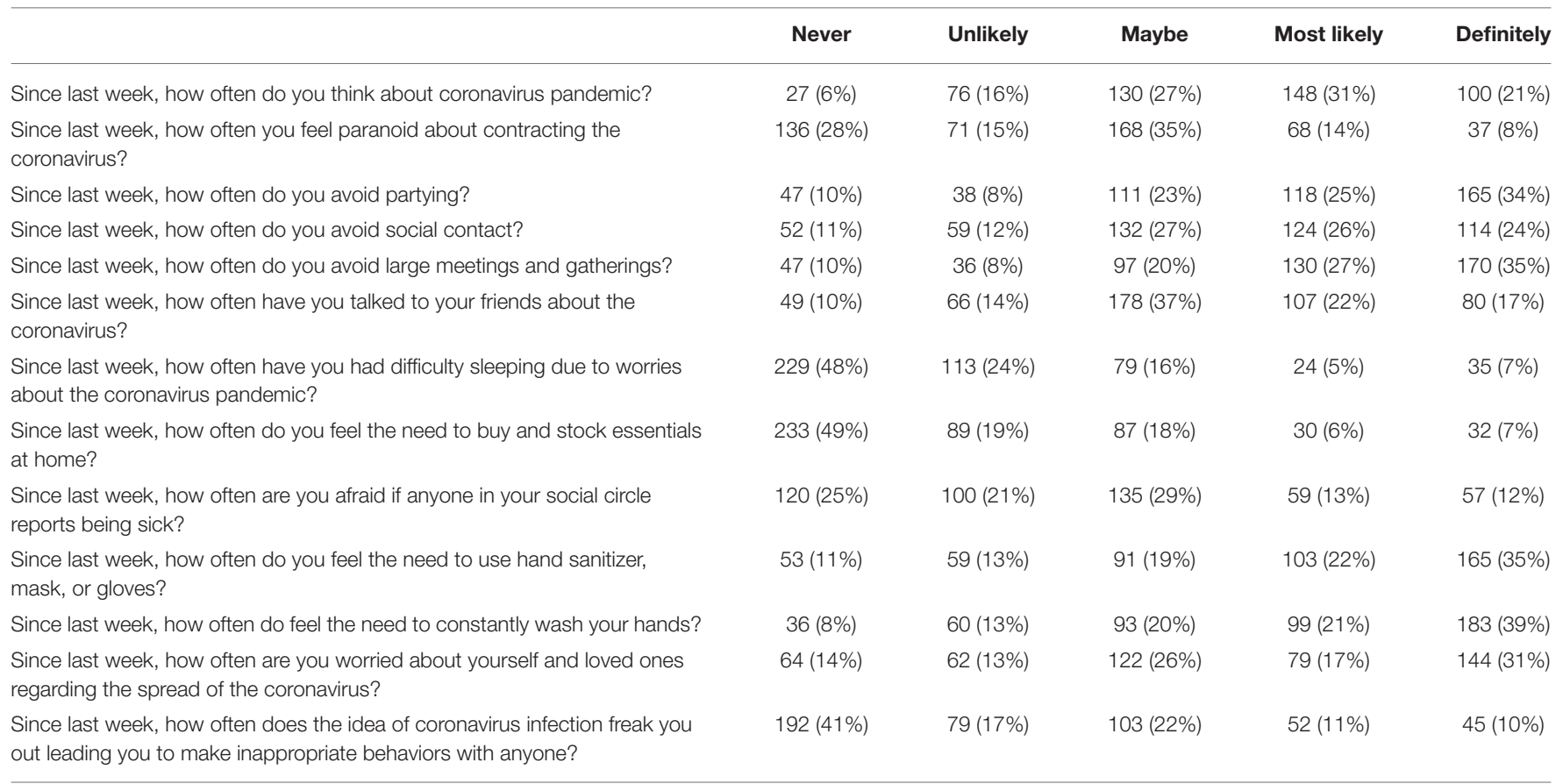

TABLE 7 | Perceived mental healthcare needs among participants.

\begin{tabular}{lrr}
\hline & Yes & Maybe \\
\hline Do you think it would be nice to talk to someone about your worries regarding the COVID-19 pandemic? & $129(27 \%)$ & $174(37 \%)$ \\
Do you think it is necessary to get mental health help if one panics because of the pandemic situation? & $247(53 \%)$ & $125(27 \%)$ \\
$\begin{array}{l}\text { Do you think it would be beneficial for mental health professionals to help people in dealing with the } \\
\text { current COVID-19 pandemic situation? }\end{array}$ & $292(62 \%)$ & $125(27 \%)$ \\
$\begin{array}{l}\text { Will you suggest obtaining mental health services for people who are highly affected by the COVID-19 } \\
\text { pandemic? }\end{array}$ & $305(64 \%)$ & $114(24 \%)$
\end{tabular}
pandemic?

Do you think it would be nice to talk to someone about your worries regarding the COVID-19 pandemic?

Do you think it is necessary to get mental health help if one panics because of the pandemic situation?

Do you think it would be beneficial for mental health professionals to help people in dealing with the current COVID-19 pandemic situation?

Will you suggest obtaining mental health services for people who are highly affected by the COVID-19 pandemic?

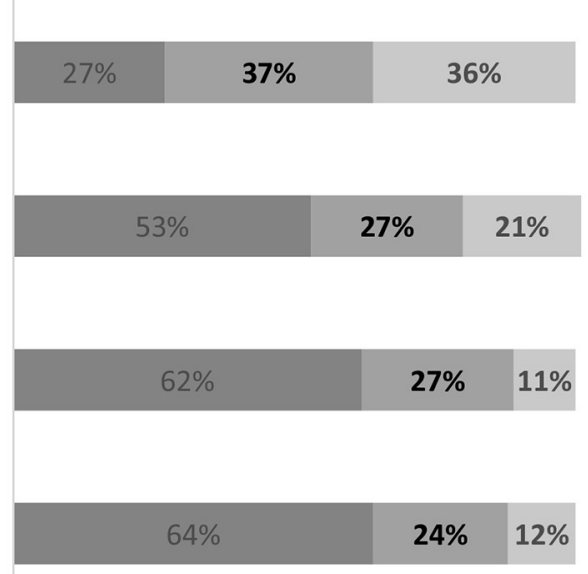

Yes Maybe $\square$ No

FIGURE 3 | Perceived mental healthcare needs among participants. 
general, updated and informed the public about COVID-19 with a focus on the publications that adversely affect people's life and health. When the media reporting negative stories constantly, the audience most likely to carry negative attitude toward the COVID-19 pandemic (24). It is known that attitude is associated with a person's response to the surrounding stimuli. The study participants showed a significant increase in following protective measures such as wearing face coverings, washing hands, social distancing, and self-quarantining if they felt ill (25). These behaviors indicate high concern of contracting COVID19. Thus, a negative attitude is expected as media coverage overwhelmingly showed the negative side of the pandemic on individuals and public health. It could play protective roles in pandemic situations.

As COVID-19 affects a large proportion of society, a variety of preventive measures were implemented at the personal and societal level, such as limiting daily activities and social interaction. Removing people from their work, education, and social activities, though beneficial to slowing virus transmission, took a toll on mental health, causing individuals to experience panic, stress, confusion, and sleep problems. Additionally, people may become worried about unexpected health problems, causing them additional stress, and misinformation about the pandemic can lead to fear and panic. Approximately half of study participants often feel worried about their own risk of becoming infected by the virus, as well as family and friends. The results of this study suggested that COVID-19 increased anxiety and stress levels among participants. These findings are consistent with those found in the literature in the last few months (26-31). COVID-19 can be the cause of high anxiety, especially among the elderly or those with chronic health problems (32). Hence, it is likely that the COVID-19 pandemic has contributed to poor mental health outcomes. For example, the U.S. Census Bureau Household Pulse Survey reported a significant increase of anxiety and depression symptoms in May 2020 (33) compared to the first 3 months of 2019. The world has passed through an historic pandemic and the evidence has shown detrimental effects on mental health $(34,35)$. COVID-19 is unprecedented in terms of economic lockdown and social isolation, as is its significant impact on mental health in all age groups (36).

In this study, over half of the participants thought it would be nice to talk to someone about their worries regarding the COVID-19 epidemic. Most study participants approved of providing mental health services to those affected by the pandemic. However, access to mental health services was very limited in Saudi Arabia-due to stigma about mental illness-prior to the pandemic and could be inaccessible during and after the pandemic. Therefore, mental health problems could be expected to continue and worsen with time if no psychological intervention were provided. Thus, it is recommended that individuals be encouraged to obtain mental health services, and that these services be made accessible for anyone who requires them. Online mental health consultations are another option, which might reduce any stigma resulting from visiting mental health clinics.
Undoubtedly, there is a need to focus more on strategies to help and support those at risk of developing mental health issues. Health education is critical at this point to reach out to community members and provide mental health guidelines. Enhancing access to psychological interventions is important at this time with new approaches such as webbased intervention and telepsychiatry. This cannot be done without collaboration and support from Saudi health authorities. In addition, health authorities must regularly provide updates regarding the pandemic, including effective prevention measures, vaccines, and new emerging threats, and fight misinformation and rumors, especially about the safety and efficacy of the COVID-19 vaccines. Accurate health information could counter negative thinking and buffer anxiety, stress, and depression.

The study limitation includes a sampling bias, as the study targeted only individuals who had access to the Internet, used What's App, and were linked directly or indirectly to the study investigators. This was evidenced by the fact that the median age is 23 years. Given that the sample size is also small, it is imperative that the findings cannot be generalized to the whole of Saudi society. In addition, causal inferences cannot be made with a cross-sectional study design.

\section{CONCLUSION}

The findings of this study reveal that most people have developed a satisfactory level of knowledge about the coronavirus and possible preventive measures to limit its transmission. However, respondents experienced worries and fears about the virus, particularly about being infected. The perceived threat of infection could lead adverse psychological outcomes such as health anxiety, stress, and depression. Therefore, there is an urgent need for more health education and awareness programs to make individuals cautious not to panic about COVID-19 and its variants. Ongoing educational programs may alleviate negative attitudes and encourage constructive preventive and restorative practices.

\section{DATA AVAILABILITY STATEMENT}

The raw data supporting the conclusions of this article will be made available by the authors, without undue reservation.

\section{ETHICS STATEMENT}

Ethical review and approval was not required for the study on human participants in accordance with the local legislation and institutional requirements. The patients/participants provided their written informed consent to participate in this study.

\section{AUTHOR CONTRIBUTIONS}

All authors contributed equally to the conception and design, acquisition of data, or analysis and interpretation of data, took 
part in drafting the article or revising it critically for important intellectual content, gave final approval of the version to be published, and agreed to be accountable for all aspects of the work.

\section{ACKNOWLEDGMENTS}

We thank to the cooperation and support of all the respondents for the time and effort that they devoted to the study.

\section{REFERENCES}

1. Drosten C, Günther S, Preiser W, Van Der Werf S, Brodt H, Becker S, et al. Identification of a novel coronavirus in patients with severe acute respiratory syndrome. N Engl J Med. (2003) 348:1967-76. doi: 10.1056/NEJMoa030747

2. Zaki AM, Van Boheemen S, Bestebroer TM, Osterhaus AD, Fouchier RA. Isolation of a novel coronavirus from a man with pneumonia in Saudi Arabia. N Engl J Med. (2012) 367:1814-20. doi: 10.1056/NEJMoa1211721

3. Shinoda S, Karaki H, Hayashi H. Special issue on COVID-19 and historical pandemics. J Disaster Res. (2021) 16:5. doi: 10.20965/jdr.2021.p0005

4. Fung TS, Liu DX. Similarities and dissimilarities of COVID19 and other coronavirus diseases. Annu Rev Microbiol. (2021) 25:75. doi: 10.1146/annurev-micro-110520-023212

5. WHO. Coronavirus Disease (COVID-19) Pandemic. (2021). Available online at: https://www.who.int/emergencies/diseases/novel-coronavirus-2019 (accessed February 2, 2021).

6. Vitenu-Sackey PA, Barfi R. The impact of covid-19 pandemic on the global economy: emphasis on poverty alleviation and economic growth. Econ Finance Lett. (2021) 8:32-43. doi: 10.18488/journal.29.2021.81.32.43

7. Nigrovic PA. COVID-19 cytokine storm: what is in a name?le. Ann Rheum Dis. (2021) 80:3-5. doi: 10.1136/annrheumdis-2020-219448

8. World Health Organization. Coronavirus Disease 2019. (COVID-19): Situation Report, 86. (2020). Available online at: https://www.who.int/publications/i/ item/coronavirus-disease-2019- (covid-19) (accessed August 17, 2021).

9. Msmali AH, Mutum ZM, Mechai I, Ahmadini AA. Modeling and simulation: a study on predicting the outbreak of COVID-19 in Saudi Arabia. medRxiv. (2021) 2021:5522928. doi: 10.1155/2021/5522928

10. Reuben RC, Danladi MM, Saleh DA, Ejembi PE. Knowledge, attitudes and practices towards COVID-19: an epidemiological survey in North-Central Nigeria. J Community Health. (2020) 46:457-70. doi: 10.1007/s10900-020-00881-1

11. Zhong B, Luo W, Li H, Zhang Q, Liu X, Li W, et al. Knowledge, attitudes, and practices towards COVID-19 among Chinese residents during the rapid rise period of the COVID-19 outbreak: a quick online cross-sectional survey. Int J Biol Sci. (2020) 16:1745. doi: 10.7150/ijbs.45221

12. Azlan AA, Hamzah MR, Sern TJ, Ayub SH, Mohamad E. Public knowledge, attitudes and practices towards COVID-19: a cross-sectional study in Malaysia. PLoS ONE. (2020) 15:e0233668. doi: 10.1371/journal.pone. 0233668

13. Sari DK, Amelia R, Dharmajaya R, Sari LM, Fitri NK. Positive correlation between general public knowledge and attitudes regarding COVID-19 outbreak 1 month after first cases reported in Indonesia. J Community Health. (2021) 46:182-9. doi: 10.1007/s10900-020-00866-0

14. Brislin RW. Back-translation for cross-cultural research. J Cross Cult Psychol. (1970) 1:185-216. doi: 10.1177/135910457000100301

15. Brislin RW. The wording and translation of research instruments. In: Lonner WJ, Berry JW, editors. Field Methods Cross-Cultural Research. Sage Publications, Inc. (1986) 137-64.

16. Roy D, Tripathy S, Kar SK, Sharma N, Verma SK, Kaushal V. Study of knowledge, attitude, anxiety \& perceived mental healthcare need in Indian population during COVID-19 pandemic. Asian J Psychiatr. (2020) 51:102083. doi: 10.1016/j.ajp.2020.102083

17. Desalegn Z, Deyessa N, Teka B, Shiferaw W, Hailemariam D, Addissie A, et al. COVID-19 and the public response: knowledge, attitude and practice of the public in mitigating the pandemic in Addis Ababa, Ethiopia. PLoS ONE. (2021) 16:e0244780. doi: 10.1371/journal.pone.0244780

18. Van Scoy LJ, Miller EL, Snyder B, Wasserman E, Chinchilli VM, Zgierska $\mathrm{AE}$, et al. Knowledge, perceptions, and preferred information sources related to COVID-19 among central pennsylvania adults early in the pandemic: a mixed methods cross-sectional survey. Ann Family Med. (2021) 19:293301. doi: 10.1370/afm.2674

19. Hamza MS, Badary OA, Elmazar MM. Cross-sectional study on awareness and knowledge of COVID-19 among senior pharmacy students. J Community Health. (2021) 46:139-46. doi: 10.1007/s10900-020-00859-Z

20. Kochuvilayil T, Fernandez RS, Moxham LJ, Lord H, Alomari A, Hunt L, et al. COVID-19: knowledge, anxiety, academic concerns and preventative behaviours among Australian and Indian undergraduate nursing students: a cross-sectional study. J Clin Nurs. (2021) 30:882-91. doi: 10.1111/joc n. 15634

21. Alahdal $\mathrm{H}$, Basingab $\mathrm{F}$, Alotaibi R. An analytical study on the awareness, attitude and practice during the COVID-19 pandemic in Riyadh, Saudi Arabia. J Infect Public Health. (2020) 13:1446-52. doi: 10.1016/j.jiph.2020.06.015

22. Al-Hanawi MK, Angawi K, Alshareef N, Qattan AM, Helmy HZ, Abudawood $\mathrm{Y}$, et al. Knowledge, attitude and practice toward COVID-19 among the public in the Kingdom of Saudi Arabia: a cross-sectional study. Front Public Health. (2020) 8:217. doi: 10.3389/fpubh.2020.00217

23. Khaled A, Siddiqua A, Makki S. The knowledge and attitude of the community from the Aseer Region, Saudi Arabia, toward COVID-19 and their precautionary measures against the disease. Risk Manag Healthc Policy. (2020) 13:1825. doi: 10.2147/RMHP.S271899

24. Giri SP, Maurya AK. A neglected reality of mass media during COVID-19: effect of pandemic news on individual's positive and negative emotion and psychological resilience. Pers Individ Dif. (2021) 180:110962. doi: 10.1016/j.paid.2021.110962

25. Liu Y, Duong HT, Nguyen HT. Media exposure and intentions to wear face masks in the early stages of the COVID-19 outbreak: the mediating role of negative emotions and risk perception. Atlantic J Commun. (2021) 1-14. doi: 10.1080/15456870.2021.1951733

26. Rasmussen SA, MSJCS MD. Treatment for severe acute respiratory distress syndrome from. Ann Oncol. (2020) 20:518

27. Santabárbara J, Lasheras I, Lipnicki DM, Bueno-Notivol J, PérezMoreno M, López-Antón R, et al. Prevalence of anxiety in the COVID-19 pandemic: an updated meta-analysis of communitybased studies. Prog Neuro-Psychopharmacol Biol Psychiatry. (2021) 109:110207. doi: 10.1016/j.pnpbp.2020.110207

28. Nikčević AV, Marino C, Kolubinski DC, Leach D, Spada MM. Modelling the contribution of the Big Five personality traits, health anxiety, and COVID-19 psychological distress to generalised anxiety and depressive symptoms during the COVID-19 pandemic. J Affect Disord. (2021) 279:57884. doi: $10.1016 /$ j.jad.2020.10.053

29. Zhang Y, Ma ZF. Impact of the COVID-19 pandemic on mental health and quality of life among local residents in Liaoning Province, China: a cross-sectional study. Int J Environ Res Public Health. (2020) 17:2381. doi: 10.3390/ijerph17072381

30. Torales J, O'Higgins M, Castaldelli-Maia JM, Ventriglio A. The outbreak of COVID-19 coronavirus and its impact on global mental health. Int J Soc Psychiatry. (2020) 66:317-20. doi: 10.1177/0020764020915212

31. Özdin S, Bayrak Özdin S. Levels and predictors of anxiety, depression and health anxiety during COVID-19 pandemic in Turkish society: the importance of gender. Int J Soc Psychiatry. (2020) 66:504-11. doi: 10.1177/0020764020927051

32. Malesza M, Kaczmarek MC. Predictors of anxiety during the COVID-19 pandemic in Poland. Pers Individ Dif. (2021) 170:110419. doi: 10.1016/j.paid.2020.110419

33. Centers for Disease Control and Prevention. Anxiety and Depression Household Pulse Survey (2021). Available online at: https://www.cdc.gov/nchs/ covid19/health-care-access-and-mental-health.htm (accessed July, 2021). 
34. Jeong H, Yim HW, Song Y, Ki M, Min J, Cho J, et al. Mental health status of people isolated due to Middle East Respiratory Syndrome. Epidemiol Health. (2016) 38:e2016048. doi: 10.4178/epih.e2016048

35. Hawryluck L, Gold WL, Robinson S, Pogorski S, Galea S, Styra R, et al. Control and psychological effects of quarantine, Toronto, Canada. Emerg Infect Dis. (2004) 10:1206. doi: 10.3201/eid1007.030703

36. Santini ZI, Jose PE, Cornwell EY, Koyanagi A, Nielsen L, Hinrichsen C, et al. Social disconnectedness, perceived isolation, and symptoms of depression and anxiety among older Americans (NSHAP): a longitudinal mediation analysis. Lancet Public Health. (2020) 5:e62-70. doi: 10.1016/S2468-2667(19)30230-0

Conflict of Interest: The authors declare that the research was conducted in the absence of any commercial or financial relationships that could be construed as a potential conflict of interest.
Publisher's Note: All claims expressed in this article are solely those of the authors and do not necessarily represent those of their affiliated organizations, or those of the publisher, the editors and the reviewers. Any product that may be evaluated in this article, or claim that may be made by its manufacturer, is not guaranteed or endorsed by the publisher.

Copyright $\odot 2022$ Alanazi and Bahjri. This is an open-access article distributed under the terms of the Creative Commons Attribution License (CC BY). The use, distribution or reproduction in other forums is permitted, provided the original author(s) and the copyright owner(s) are credited and that the original publication in this journal is cited, in accordance with accepted academic practice. No use, distribution or reproduction is permitted which does not comply with these terms. 